\title{
Expectancies generated by melodic intervals: Evaluation of principles of melodic implication in a melody-completion task
}

\author{
WILLIAM FORDE THOMPSON \\ York University, North York, Ontario, Canada \\ LOLA L. CUDDY \\ Queen's University, Kingston, Ontario, Canada \\ and \\ CHERYL PLAUS \\ York University, North York, Ontario, Canada
}

\begin{abstract}
Bottom-up principles of melodic implication (Narmour, 1990) were evaluated in a melodycompletion task. One hundred subjects (50 low training; 50 high training in music) were presented each of eight melodic intervals. For each interval, the subjects were asked to compose a short melody on a piano keyboard, treating the interval provided as the first two notes of the melody. For each melody, the first response-the note immediately following the initial interval-was analyzed. Multinomial log linear analyses were conducted to assess the extent to which responses could be predicted by Narmour's (1990, 1992) bottom-up principles. Support was found for all of Narmour's principles, and two additional predictors based on implied tonal structure. Responses of low- and high-training groups were similar.
\end{abstract}

The ability to anticipate events is highly adaptive. Expectancies enable organisms to respond rapidly and effectively to potentially useful or harmful stimuli. In view of the survival benefits, it is likely that expectancies are controlled, at least in part, by innate mechanisms attuned to the properties of the sensory environment. In this study, we considered a specific proposal for the operation of innate, "bottom-up" principles for melodic expectancy in music (Narmour, 1990, 1992).

In theoretical discussions of music, expectancy is thought to play a special role in the formation of emotional and affective responses (Meyer, 1956). According to Meyer, emotion and affect are heightened when a listener's musical expectations are unfulfilled. A number of psychological studies of music have examined the formation of expectancies during music listening. These studies have established that musical expectancies are shaped by rhyth-

This research was funded by grants from the Natural Sciences and Engineering Research Council of Canada awarded to W.F.T. and L.L.C. We thank Eugene Narmour, Neil Macmillan, Richard Parncutt, and an anonymous reviewer for helpful comments on earlier versions of the manuscript and E. Glenn Schellenberg for statistical advice. We thank J. C. Carlsen for permission given to L.L.C. to access the data from Carlsen (1981). Research assistance was provided by Doug Gifford, Alistair McKinnell, and Frank Russo. Correspondence concerning this article should be addressed to W. F. Thompson, Department of Psychology, Atkinson College, York University, 4700 Keele Street, North York, ON, Canada M3J 1P3, or to L. L. Cuddy, Department of Psychology, Queen's University, Kingston, ON, Canada K7L 3N6 (e-mail: billt@yorku.ca). mic or metric pattern (Jones, 1981, 1982, 1990), tonal and harmonic structure (Schmuckler, 1989, 1990), and melodic structure (e.g., Carisen, 1981, 1990; Cuddy \& Lunney, 1995; Krumhansl, 1995).

In this study, we examined the formation of melodic expectancies in a melody-completion task. Our goal was to evaluate the principles of melodic implication outlined in Narmour's $(1989,1990,1992)$ implication-realization model of melody. Briefly, Narmour's model rests on the assumption that the perception of melodic structure is shaped by the ability to detect melodic implications. A melodic implication occurs when a melodic event generates expectations for subsequent melodic events. The absence, or suppression, of melodic implication is perceived as the termination or closure of the ongoing melodic structure. Conditions that suppress melodic implication include durational cumulation (short to long note), metric stress, and tonal stability. ${ }^{1}$

Narmour (1990) argues that perceptual expectancies in melodies are partially shaped by a small number of universal, Gestalt-like, principles (referred to by Narmour as "bottom-up" implicative principles). The two primary implicative principles are registral direction and intervallic difference. These principles operate differently for small intervals ( $\leq 5$ semitones) and large intervals ( $\geq 7$ semitones). Three other principles implicit in the implication-realization model are registral return, proximity, and closure.

Registral direction states that small intervals imply continuation in the same registral direction (e.g., up-up), whereas large intervals imply a change in registral di- 
rection (e.g., up-down; up-lateral). Intervallic difference states that small intervals imply a subsequent interval that is similar in size (i.e., the same size \pm 2 semitones if registral direction changes, the same size \pm 3 semitones if registral direction stays the same), whereas large intervals imply an interval that is relatively smaller in size (at least 3 semitones smaller if registral direction changes and at least 4 semitones smaller if registral direction stays the same. Note that a "smaller" interval is not always a "small" interval). Registral return occurs when an interval moves to a third note that is identical to or near ( \pm 2 semitones) the first note of that interval. Proximity is defined as less than or equal to 5 semitones between any 2 notes. Finally, closure occurs when there is a change in registral direction (e.g., up-down), movement to a smaller sized interval, or both. The operation of closure is not restricted to the end of musical phrases; it may also occur as an articulation within a phrase.

Figure 1 provides, for both small and large intervals, examples of continuation notes that fulfill or deny each implicative principle. An elaborated illustration of the relationship between implicative interval size and the continuations that fulfill each principle can be found in Cuddy and Lunney (1995; reprinted from Krumhansl, 1995).

In addition to the bottom-up implicative principles, Narmour $(1990,1992)$ has stressed the importance of learned (nonuniversal) influences on melodic expectancy. For example, the expectancies of most Western listeners are influenced by their knowledge of tonal structure. Thus, we also evaluated a number of principles related to implied tonal structure.

Research has established that Narmour's bottom-up principles, in combination with principles based on tonal structure, provide a good perceptual model of how peo- ple rate continuation tones presented after implicative intervals (Cuddy \& Lunney, 1995; Krumhansl, 1991, 1995). Cuddy and Lunney examined four melodic intervals in ascending and descending direction: a major second, a minor third, a major sixth, and a minor seventh. Musically trained and untrained listeners heard each interval followed by a single tone, called a continuation tone. Listeners were told to consider the initial interval to be the first 2 notes of a melody. The task was to rate, on a scale of $1-7$, how well the continuation tone followed the interval. For each interval, listeners provided ratings for 25 different continuation tones in a 2 -octave range. The mean ratings for the 200 conditions ( 25 continuation tones for each of the 4 implicative intervals in ascending and descending direction) were regressed on predictors representing Narmour's implicative principles.

Three of Narmour's principles (intervallic difference, registral return, and proximity) and a revised version of registral direction had significant predictive power in the model. The revised principle stated that large intervals implied a change in registral direction but that small intervals provided no implication for registral direction. The principle of closure had no significant predictive power in the regression model. Cuddy and Lunney (1995) also found support for a predictor based on pitch height (which predicted higher ratings for higher pitches) and two predictors related to implied tonal structure. The overall regression model accounted for $64 \%$ of the variance in mean continuation ratings.

This study involved a reexamination of the 8 implicative intervals studied by Cuddy and Lunney (1995). However, while Cuddy and Lunney obtained ratings of continuation tones presented after the implicative intervals, we asked participants to produce melodies that might follow
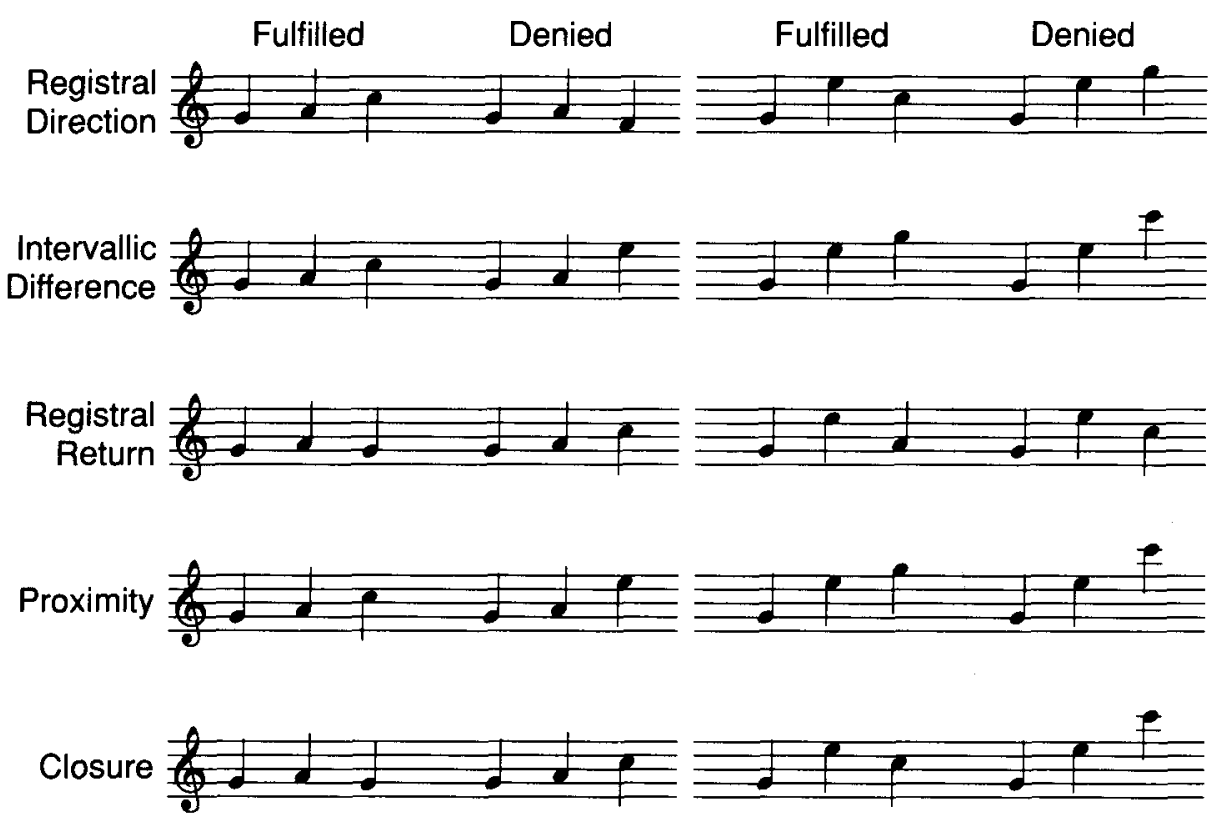

Figure 1. Examples of principle fulfillment and principle denial for small and large implicative intervals, for each of the five bottom-up principles. 
from the implicative intervals. Comparable melodycompletion studies have been reported by Carlsen (1981) and Unyk and Carlsen (1987). Carlsen presented the first 2 tones of a melody to musically trained singers from the United States, Germany, and Hungary, and asked them to sing tones that might continue the melody. Unyk and Carlsen used a similar procedure with musicians from the United States only. The researchers then examined the frequency with which different continuation tones were sung, and introduced the notion that different melodic intervals generated different expectancies. Carlsen and Unyk's studies were not intended as tests of the implicationrealization model, but their procedure may be a valuable means of assessing the model (Cuddy \& Lunney, 1995; Krumhansl, 1995).

The design of our study differed in two ways from that used by Carlsen (1981) and Unyk and Carlsen (1987). First, we asked subjects to produce continuations of melodic intervals on a piano keyboard rather than to sing them. Second, we included both musically trained and musically untrained subjects. If the implicative principles reflect universal perceptual laws, evidence for them should not depend on musical knowledge. Our subjects were asked to produce melodies for each of 8 initial intervals. Tones immediately following the initial intervals were examined. We predicted that these tones would more often realize, than deny, the implicative principles.

\section{METHOD}

\section{Subjects}

One hundred visitors to the Ontario Science Center, Toronto, 41 women and 59 men ranging in age from 16 to 62 years, participated as subjects in the study. They were divided into two groups: 50 (high-training group) had had 5 or more years of formal training in music and were all currently playing a musical instrument (range of musical training: 5-20 years); 50 (low-training group) had had less than 5 years of formal training in music and were not currently playing a musical instrument (range of training: 0-4 years). All subjects reported that they had had some experience in playing a keyboard, that they were comfortable with the task, and that they had normal hearing ability.

\section{Materials}

The stimuli consisted of 8 intervals: four interval sizes presented in both ascending and descending directions. The four interval sizes were major second, minor third, major sixth, and minor seventh. Narmour (1990) classifies the major second and minor third as small intervals, and the major sixth and minor seventh as large intervals.

Table 1

The Eight Intervals Used in the Experiment

\begin{tabular}{lll}
\hline Interval & Direction & Notes \\
\hline Major second & $\begin{array}{l}\text { ascending } \\
\text { descending } \\
\text { ascending } \\
\text { descending }\end{array}$ & $\mathrm{C}_{4}-\mathrm{D}_{4}$ \\
Minor third & $\mathrm{C}_{4}-\mathrm{Bb}_{3}$ \\
& $\mathrm{C}_{4}-\mathrm{Eb}_{4}$ \\
Major sixth & $\mathrm{C}_{4}-\mathrm{A}_{3}$ \\
& descending & $\mathrm{C}_{4}-\mathrm{A}_{4}$ \\
Minor seventh & ascending & $\mathrm{C}_{4}-\mathrm{Eb}_{3}$ \\
& descending & $\mathrm{C}_{4}-\mathrm{Bb}_{4}$ \\
& $\mathrm{C}_{4}-\mathrm{D}_{3}$ \\
\hline
\end{tabular}

The first note of every interval was middle C. Table 1 lists the intervals used.

A Roland U-20 keyboard was attached to a Macintosh 660-AV through a Roland MPU-401 MIDI interface. The keyboard was tuned to equal temperament, and the timbre was set to "piano 1." Participants wore Sennheisser HD 480 headphones, with the loudness set to a comfortable level (approximately 60-65 dB SPL).

\section{Design and Procedure}

The experimenter (C.P.) explained to each subject that we were interested in how people continued a melody when the first 2 notes of the melody were provided. For each melodic interval, the experimenter played the 2 notes on the Roland keyboard at approximately equal duration (about $1 \mathrm{sec}$ ) and loudness while the subject watched and listened. The subject was then asked to produce a melody that followed naturally from the 2 notes. The subjects were told that each melody should involve just 1 note at a time, that is, there should be no accompaniment. Melodies were composed and played on a Roland keyboard. The experimenter ensured that all subjects were comfortable playing on this keyboard and encouraged them to familiarize themselves with the keyboard before starting the experimental trials. To reduce the constraints of hand stretch, we allowed subjects to use both hands to play their melodies.

There were eight trials, one for each interval. The 8 intervals were presented in random order, determined independently for each subject. The first note of each interval was always $\mathrm{C}_{4}$. This procedure was adopted to facilitate the task for subjects with little training in music. After the two notes were presented, the subject was given approximately $10 \mathrm{sec}$ to play the keyboard and decide on how the melody should be completed. The subject indicated to the experimenter when he or she was ready to produce the melody. The experimenter then recorded the melody onto a Macintosh 660-AV computer, running the music sequencing software MusicShop.

\section{RESULTS}

\section{Description of Melodies}

The 800 melodies ( 8 melodies for each of the 100 subjects) ranged in length from 5 to 58 notes, with a mean length of 16.34 notes. Table 2 shows the first 10 pitches for eight examples of melodies produced, where each example was produced by a different subject for a different implicative interval. Melodies varied in length, pitch range, contour pattern, rhythmic structure, and tempo, but were generally produced within a Western tonal framework. Across subjects and implicative intervals, note selections were most consistent with the key of $\mathrm{C}$ major (the major key built on the first note of the implicative interval). This adherence to tonal structure was observed by recording the frequency with which each of the 12 pitch classes in the chromatic scale was selected. First, the first 5 notes produced (i.e., the third to seventh note positions) were diatonic to the key of $\mathrm{C}$ major in $92 \%, 86 \%$, $87 \%, 82 \%$, and $88 \%$ of the melodies, respectively. Second, for these same five note positions, the rank order (Spearman) correlation between the set of response frequencies (for the 12 pitch classes of the chromatic scale) and Krumhansl and Kessler's (1982) C-major tonal hierarchy was $.95, .85, .86, .89$, and .87 , respectively. These correlations indicate that subjects adhered to a tonal framework from the first note produced and maintained this tonal structure for subsequent notes. 
Table 2

Eight Examples of Pitch Sequences Produced by Subjects

\begin{tabular}{ccc}
\hline Implicative Interval & \multicolumn{1}{c}{ 10 Subsequent Pitches Produced } & Training \\
\hline $\mathrm{C}_{4}-\mathrm{D}_{4}$ & $\mathrm{E}_{4}-\mathrm{D}_{4}-\mathrm{C}_{4}-\mathrm{C}_{4}-\mathrm{E}_{4}-\mathrm{F}_{4}-\mathrm{G}_{4}-\mathrm{G}_{4}-\mathrm{G}_{4}-\mathrm{A}_{4} \ldots$ & high \\
$\mathrm{C}_{4}-\mathrm{Bb}_{3}$ & $\mathrm{~A}_{3}-\mathrm{G}_{3}-\mathrm{F}_{3}-\mathrm{E}_{3}-\mathrm{D}_{3}-\mathrm{C}_{3}-\mathrm{E}^{b_{3}}-\mathrm{A}_{3}-\mathrm{Bb}_{3}-\mathrm{C}_{4} \cdots$ & low \\
$\mathrm{C}_{4}-\mathrm{E}_{4}$ & $\mathrm{C}_{4}-\mathrm{G}_{4}-\mathrm{F}_{4}-\mathrm{E}_{4}-\mathrm{D}_{4}-\mathrm{Eb}_{4}-\mathrm{C}_{4}-\mathrm{F}_{4}-\mathrm{D}_{4}-\mathrm{C}_{4} \ldots$ & high \\
$\mathrm{C}_{4}-\mathrm{A}_{3}$ & $\mathrm{G}_{3}-\mathrm{F}_{3}-\mathrm{E}_{3}-\mathrm{D}_{3}-\mathrm{E}_{3}-\mathrm{E}_{3}-\mathrm{F}_{3}-\mathrm{A}_{3}-\mathrm{A}_{3}-\mathrm{G}_{3} \ldots$ & low \\
$\mathrm{C}_{4}-\mathrm{A}_{4}$ & $\mathrm{G}_{4}-\mathrm{F}_{4}-\mathrm{D}_{4}-\mathrm{C}_{4}-\mathrm{A}_{4}-\mathrm{G}_{4}-\mathrm{E}_{4}-\mathrm{D}_{4}-\mathrm{C}_{4}-\mathrm{F}_{4} \ldots$ & high \\
$\mathrm{C}_{4}-\mathrm{E}_{3}$ & $\mathrm{C}_{4}-\mathrm{Ab}_{3}-\mathrm{G}_{3}-\mathrm{Ab}_{3}-\mathrm{F}_{3}-\mathrm{A}_{3}-\mathrm{Eb}_{3}-\mathrm{Eb}_{3}-\mathrm{C}_{4}-\mathrm{A}_{3} \ldots$ & low \\
$\mathrm{C}_{4}-\mathrm{Bb}_{4}$ & $\mathrm{Ab}_{4}-\mathrm{G}_{4}-\mathrm{Ab}_{4}-\mathrm{Bb}_{4}-\mathrm{G}_{4}-\mathrm{F}_{4}-\mathrm{Eb}_{4}-\mathrm{F}_{4}-\mathrm{D}_{4}-\mathrm{E}_{4} \ldots$ & high \\
$\mathrm{C}_{4}-\mathrm{D}_{3}$ & $\mathrm{E}_{3}-\mathrm{C}_{4}-\mathrm{F}_{3}-\mathrm{C}_{4}-\mathrm{G}_{3}-\mathrm{C}_{4}-\mathrm{A}_{3}-\mathrm{G}_{3}-\mathrm{F}_{3}-\mathrm{E}_{3} \ldots$ & low \\
\hline
\end{tabular}

\section{Assessment of Implicative Principles}

Further analyses were restricted to the 3 rd note of each melody, that is, the note immediately following the interval provided by the experimenter. The appendix shows the frequency with which different notes were selected at the third note position, for each of the 8 intervals presented. Table 3 shows the percentage of these selections that are in agreement with each of Narmour's implicative principles across the 8 intervals, and an estimate of percentages expected by chance. The principle of closure is divided into its two subcomponents.

The table shows a high degree of correspondence between the two groups of subjects. For both trained and untrained groups, responses were highly compatible with most of the principles. Registral direction, intervallic difference, proximity, and closure were fulfilled in a high percentage of responses. Only registral return was fulfilled in a low percentage of responses.

In interpreting these percentages, one must recognize that the principles differ from each other in the number of possible realizations and, hence, in the percentages expected by chance. For example, the principle of registral direction is more likely to be satisfied by chance than is the principle of registral return (for which only 5 notes fulfill the principle for each interval). The chance estimates listed in Table 3 were based on random responding across a 2-octave (25-note) range, from 1 octave above to 1 octave below the 2 nd note of the initial interval. Estimates were based on this range because responses in this range can be made quite comfortably, whereas it would

Table 3

Percent Responses Fulfilling Each Principle for Lowand High-Training Groups

\begin{tabular}{|c|c|c|c|}
\hline \multirow[b]{2}{*}{ Implicative Principle } & \multicolumn{2}{|c|}{ Musical Training } & \multirow{2}{*}{$\begin{array}{c}\text { Estimate of } \\
\text { Percentage } \\
\text { Expected by } \\
\text { Chance }\end{array}$} \\
\hline & Low & High & \\
\hline Registral direction & $75.75 \dagger$ & $74.50 \dagger$ & 50.00 \\
\hline Intervallic difference & $82.75 \dagger$ & $86.25 \dagger$ & 47.00 \\
\hline Registral return & $28.25^{*}$ & 26.75 n.s. & 20.00 \\
\hline Proximity & $77.75 \dagger$ & $83.50 \dagger$ & 44.00 \\
\hline $\begin{array}{l}\text { Closure } \\
\text { (change in direction) }\end{array}$ & $67.75 \dagger$ & $67.00 \dagger$ & 52.00 \\
\hline $\begin{array}{l}\text { Closure } \\
\text { (movement to smaller interval) }\end{array}$ & $51.33 \dagger$ & $55.33 \dagger$ & 21.33 \\
\hline
\end{tabular}

Note-Percentages expected by chance were estimated for random responding across a 2 -octave (25-note) range. Significance on the chisquare statistic: ${ }^{*} p<.05 ;{ }^{\dagger} p<.01$. be physically difficult to use the entire range of the keyboard (i.e., 5 octaves). ${ }^{2}$ Estimates based on random responding across a larger range would be lower for all principles except registral direction, for which it would be the same. Table 3 shows significance levels for chisquare tests applied separately to each principle and group of subjects. With the exception of registral return for musically trained listeners, each principle was fulfilled significantly more often than would be expected by chance.

Spearman (rank-order) correlation was used to assess the similarity in responses made by trained and untrained participants. For each group, the frequency of responses was entered across a 2-octave range for each intervalfrom 1 octave above to 1 octave below the 2 nd tone of the initial interval. The data for all 8 intervals were then entered into a single array (i.e., 8 intervals $\times 25$ notes $=$ 200 cells). The high- and low-training groups showed a similar pattern of results $[r(198)=.75, p<.001]$.

Multinomial log linear analysis was next adopted to assess how well the combined set of principles could predict the pattern of responses, and to evaluate the independent contribution of each implicative principle (some of the principles make overlapping predictions). The goal of multinomial log linear analysis is comparable to multiple regression. Unlike multiple regression, however, $\log$ linear analysis does not require that the dependent variabie be measured along an interval scale. It is therefore more suited to the frequency data collected here. It works by finding an optimal set of weights such that a weighted sum of predictor variables (the principles) plus a constant approximates the logarithm of values of the dependent variable (in this case, the logarithm of response frequencies). The analysis provides a measure of the overall predictive power of the set of predictors, and the unique contribution of each predictor. If the unique contribution of an individual predictor is statistically significant, that indicates that the predictor has independent predictive power-that is, predictive power not shared with any other predictor.

First, we assessed the predictive power of the five implicative principles (the base model): registral direction, intervallic difference, registral return, proximity, and closure. To perform the log linear analysis, we converted each principle into a coded variable. The coded variables were the same as those described by Krumhansl (1995). For registral direction, intervallic difference, and regis- 
tral return, we assigned 1 for notes that fulfilled the principle and 0 for notes that did not fulfill the principle. Proximity and closure were coded in a graded way. For proximity, we assigned the values $6,5,4,3,2,1$ if the 3 rd note was $0,1,2,3,4$, and 5 semitones from the previous note, respectively. Zero was assigned if the 3 rd note was greater than 5 semitones from the previous note. For closure, we assigned 0 if the note did not fulfill either condition of closure (i.e., a change in registral direction or movement to a smaller interval), 1 if the note fulfilled one condition for closure, and 2 if the note fulfilled both conditions for closure. Modified versions of the principles were also assessed (e.g., see Schellenberg, 1996), but none was as successful as the original coding.

Table 4 summarizes the results for the low-training group, the high training group, and the two groups combined (combined group). For each criterion variable (low training, high training, combined), the table illustrates the proportion of total deviance explained by the model $\left(R^{2 *}\right)$, the proportion of deviance uniquely explained by each predictor $\left(s r^{2 *}\right)$, and the odds ratio for each predictor. ${ }^{3}$

For each group, the model significantly reduced the deviance, or unexplained variance (chi-square distribution), from the independence model. For the low- and high-training groups, the proportion of total deviance explained by the model was $R^{2 *}=.46$ and $R^{2 *}=.45$, respectively. For the combined group, the proportion of total deviance explained by the model was $R^{2 *}=.48$. It may be noted that some of this explained deviance can be accounted for by more than one predictor. The extent to which principles share predictive power may be deduced by summing the proportion of deviance uniquely explained by each predictor $\left(s r^{2 *}\right)$ and comparing this value to the proportion of deviance explained by the full model. For the combined data, the sum of $s r^{2 *}$ values equals .35 and the proportion of deviance explained by the model is .48 . This comparison indicates that $13 \%$ of the deviance in frequencies can be accounted for by more than one predictor.

For both groups and for groups combined, all five predictors had significant predictive power in the model. Examination of $s r^{2 *}$ values indicates that registral direc- tion was the strongest predictor, uniquely accounting for between $14 \%$ and $18 \%$ of the deviance. In contrast, the predictive power of closure was weak, uniquely accounting for less than $1 \%$ of the deviance.

Next, we examined whether the unexplained deviance could be further reduced by introducing predictors based on implied tonal structure. Two tonality predictors, tonal hierarchy and diatonicism, were included in the final model. Tonal hierarchy predicts that responses should reflect the tonal stability of notes in the major key based on the 1st note as tonic (i.e., $\mathrm{C}$ major). Krumhansl and Kessler's (1982) tonal hierarchy values were used to quantify tonal stability. Diatonicism predicts that listeners should select melody notes that are diatonic (scale notes) in the major key based on the 1 st note as being tonic. For both predictors, we initially considered four possible implied tonalities, because each of the 2 notes of the initial interval might have been interpreted as the tonic of either a major or a minor key. However, no other tonal interpretation provided as much predictive power as that of the major key based on the 1 st note as being tonic.

Two other tonality predictors were also evaluated but were not included in the model because their contribution was negligible. These predictors, tonal region and tonal strength, represent flexible interpretations of tonal structure, and were significant predictors in the regression model reported by Cuddy and Lunney (1995). While the key for tonal hierarchy and diatonicism is defined by 1 note of the implicative interval, the keys for tonal region and tonal strength depend on both the implicative interval and the continuation note (for further details, see Cuddy \& Lunney, 1995).

Table 5 shows the results for the low-training group, the high-training group, and the combined group. For both the low- and high-training groups, the proportion of total deviance explained by the extended model was $R^{2 *}=.75$. For the combined group, the proportion of total deviance explained by the model was $R^{2 *}=.79$. A comparison of $R^{2 *}$ values in Tables 4 and 5 reveal that adding predictors based on implied tonal structure increased the explained deviance by approximately $30 \%$. The comparatively small values of $s r^{2 *}$ for these two pre-

Table 4

Results of the Log Linear Analysis in Which Narmour's Five Principles (the Base Model) Are Tested for the Low-Training Group, the HighTraining Group, and the Two Groups Combined

\begin{tabular}{|c|c|c|c|c|c|c|c|c|c|}
\hline & \multicolumn{9}{|c|}{ Group } \\
\hline & \multicolumn{3}{|c|}{ Low-Training } & \multicolumn{3}{|c|}{ High-Training } & \multicolumn{3}{|c|}{ Combined } \\
\hline & $R^{2 *}$ & O.R. & $s r^{2 *}$ & $R^{2 *}$ & O.R. & $s r^{2 *}$ & $R^{2 *}$ & O.R. & $s r^{2 *}$ \\
\hline Base model & .46 & & & .45 & & & .48 & & \\
\hline Registral direction & & 5.80 & .177 & & 5.04 & .136 & & 5.39 & .165 \\
\hline Intervallic difference & & 4.07 & .071 & & 5.78 & .093 & & 4.81 & .087 \\
\hline Registral return & & 3.61 & .079 & & 3.43 & .057 & & 3.51 & .071 \\
\hline Proximity & & 1.15 & .022 & & 1.14 & .018 & & 1.14 & .022 \\
\hline Closure & & 1.36 & .006 & & 1.28 & .003 & & 1.32 & .005 \\
\hline
\end{tabular}

Note-The results include the proportion of total deviance explained by the model $\left(R^{2 *}\right)$, the odds ratios (O.R.) for each predictor variable, and the proportion of deviance uniquely explained by each predictor $\left(s r^{2 *}\right)$. All predictors are statistically significant. 
Table 5

Results of the Log Linear Analysis in Which Narmour's Five Principles and Two Predictors Based on Implied Tonal Structure (Extended Model) Are Tested for the Low-Training Group, the High-Training Group, and the Two Groups Combined

\begin{tabular}{|c|c|c|c|c|c|c|c|c|c|}
\hline & \multicolumn{9}{|c|}{ Group } \\
\hline & \multicolumn{3}{|c|}{ Low-Training } & \multicolumn{3}{|c|}{ High-Training } & \multicolumn{3}{|c|}{ Combined } \\
\hline & $R^{2 *}$ & O.R. & $s r^{2 *}$ & $R^{2 *}$ & O.R. & $s r^{2 *}$ & $R^{2 *}$ & O.R. & $s r^{2 *}$ \\
\hline Extended model & .75 & & & .75 & & & .79 & & \\
\hline Registral direction & & 3.47 & .185 & & 5.37 & .144 & & 5.69 & .174 \\
\hline Intervallic difference & & 6.08 & .052 & & 4.85 & .070 & & 4.06 & .064 \\
\hline Registral return & & 3.16 & .061 & & 2.92 & .041 & & 3.04 & .054 \\
\hline Proximity & & 1.19 & .030 & & 1.18 & .025 & & 1.19 & .029 \\
\hline Closure & & 1.45 & .009 & & 1.38 & .006 & & 1.41 & .008 \\
\hline Tonal hierarchy & & 1.37 & .046 & & 1.42 & .049 & & 1.39 & .050 \\
\hline Diatonicism & & 3.68 & .050 & & 4.64 & .054 & & 4.09 & .055 \\
\hline
\end{tabular}

Note - The results include the proportion of total deviance explained by the model $\left(R^{2 *}\right)$, the odds ratios (O.R.) for each predictor variable, and the proportion of deviance uniquely explained by each predictor $\left(s r^{2 *}\right)$. All predictors are statistically significant.

dictors indicate that much of this additional predictive power was shared by the two predictors. ${ }^{4}$

\section{DISCUSSION}

The results of this study indicate that melody production tasks engage expectancies in a manner predictable from Narmour's bottom-up principles of melodic implication and predictors based on implied tonal structure. All five bottom-up implicative principles were supported in the study. Together with previous reports (e.g., Cuddy \& Lunney, 1995; Krumhansl, 1995; Thompson \& Stainton, 1995/1996), the findings provide strong evidence for the predictive power of the implicative principles.

The present investigation differs from previous studies of the implication-realization model in both experimental design and modeling approach. For example, we used multinomial log linear analysis to model melody production data, while the studies of Krumhansl (1995) and Cuddy and Lunney (1995) used multiple regression to model mean ratings of continuation tones. In spite of these differences, our findings are convergent with previous results.

In a study described by Krumhansl (1995), listeners were asked to rate the goodness of fit of continuation tones following melodic fragments (several bars) of British folk songs, atonal songs, and Chinese songs. Fragments were selected such that the final interval was strongly implicative. Mean ratings of continuation tones were modeled by an extended version of the implicative principles with multiple $R$ values of $.85, .71$, and .85 for British folk songs, atonal songs, and Chinese folk songs, respectively. The proportion of explained variance for British and Chinese folk songs $\left(R^{2}=.72\right)$ is close to our estimate of the deviance explained by Narmour's implicative principles and predictors based on tonality $\left(R^{2 *}\right.$ $=.75$ for both untrained and trained listeners).
Continuing this line of research, Cuddy and Lunney (1995) presented listeners with each of 8 intervals, and asked them to rate the goodness of fit of continuation tones across a 2-octave range. Mean ratings were modeled by Narmour's five principles with a multiple $R$ value of .54 and by an extended model (which included tonal strength, tonal region, and pitch height) with a multiple $R$ value of .80. The proportion of explained variance for both the base model $\left(R^{2}=.29\right)$ and the extended model $\left(R^{2}=.64\right)$ is somewhat less than the proportion of deviance explained by the base and extended models in this study.

To compare our results with those of comparable studies involving multinomial log linear analyses, we reanalyzed the responses of the American listeners in Carlsen's (1981) study, considering just the stimulus intervals tested in the present study (ascending and descending major second, minor third, major sixth, and minor seventh; see also Schellenberg, 1996, for an analysis of Carlsen's data that included other intervals). Carlsen presented musically trained singers with the first 2 notes of a melody, and asked them to sing tones that might continue the melody. Multinomial log linear analysis revealed that our extended model (the five implicative principles, tonal hierarchy, and diatonicism) accounted for .63 of the deviance in responses, with all predictors making a significant contribution to the model. This proportion is close to the proportion of explained variance reported by Cuddy and Lunney (1995) for their extended model, but less than the proportion of deviance explained for either group in the present study.

Thompson and Stainton (1995/1996) also used multinomial log linear analysis to evaluate Narmour's implicative principles, but with a very different data set. Implicative intervals were identified in 50 Bach chorales (soprano and bass voices) and in 16 Schubert melodies. Intervals were labeled as implicative if 2 sequential notes moved to a weaker metric position and decreased or did 
not change in tonal stability and duration. Multinomial $\log$ linear analysis was used to model the pattern of continuations from implicative intervals. The proportion of deviance explained by Narmour's five implicative principles was .60 for Bach soprano voices, .53 for Bach bass voices, and .44 for Schubert melodies (construction of the database did not permit an analysis of predictors based on tonality). The average of these proportions, .52 , is slightly greater than the proportion of deviance explained by Narmour's five principles in this study (see Table 4).

Although there is some consistency between studies in the overall predictive power of models based on Narmour's implication-realization model, there are differences between studies in the choice of principles and in the unique predictive power attributed to specific principles. In this investigation, comparatively strong support was found for the principle of registral direction and comparatively weak support was found for the principle of closure. The strong contribution by registral direction contrasts with the findings of Cuddy and Lunney (1995), who found only a weak contribution by registral direction. The weak contribution by closure, however, is consistent with Cuddy and Lunney's results, which showed no contribution of closure in predicting mean ratings of continuation notes following an initial 2 notes. In both studies, a weak contribution of closure may simply indicate that listeners do not expect closure to occur on the 3rd note of a melody. Similarly, our reanalysis of Carlsen's (1981) data revealed an odds ratio for closure of less than 1.0 , indicating that the odds were greater that closure would not be fulfilled on the 3 rd note. Evidently, subjects in that study tended to sing their continuations in a way that avoided closure (see also, Schellenberg, 1996, p. 114).

Predictors based on implied tonal structure-tonal hierarchy and diatonicism - contributed considerable predictive power, accounting for an additional $30 \%$ of the deviance in response frequencies. It is likely that production demands and a consistent starting note (middle C) prompted subjects in this study to treat the 1 st note as the tonic and to compose their melodies in a strongly tonal framework. It is also possible that notes in the key of $\mathrm{C}$ major were more familiar to participants and easier to play.

The tonal hierarchy was also a significant predictor in Krumhansl's (1995) perceptual study, in which listeners heard several bars of music before the implicative interval. However, the unique contribution of tonality was quite small for those data, even when musical stimuli were taken from English folk songs (see Schellenberg's, 1996, analysis of these data). Cuddy and Lunney (1995) found that when the more flexible tonality predictors of tonal region and tonal strength were added to their final regression model, tonal hierarchy could be dropped without significant loss in prediction. Unlike the tonal hierarchy predictor, tonal region and tonal strength allow for a shifting interpretation of tonal structure for different continuation tones. By changing the starting note for dif- ferent trials, Cuddy and Lunney may have encouraged listeners to shift their tonal interpretation from trial to trial.

Results for both groups of participants (low- and highmusical training) were similar. This similarity, also reported by Cuddy and Lunney (1995), held both for the analysis of Narmour's bottom-up principles (Table 4) and for the analysis that included style-specific predictors reflecting tonal knowledge (Table 5). Two of Narmour's (1990) assertions are therefore supported. The first is that the operation of the bottom-up principles is not dependent on formal training in music. The second is that melodic expectancies are influenced by both bottom-up and style-specific factors. Whether the close correspondence between the results of the two training levels reflects innate predispositions, long-term informal exposure to Western tonal-harmonic music, or the combined influence of predisposition and exposure is, of course, a matter for future research.

Combining the bottom-up principles with the tonal hierarchy and diatonicism gave rise to an extended model of melodic expectancy that accounted for $79 \%$ of the deviance in responses of the low- and high-training groups combined. This strong support for an extended model of melodic implication corroborates the perceptual studies of Krumhansl (1995), Cuddy and Lunney (1995), and others, and in view of that work, implies that the perception and production of melodies follow similar principles of expectancy (see also, Palmer, 1992; Schmuckler, 1989, 1990). More generally, perception and production tasks appear to engage multiple melodic expectancies.

\section{REFERENCES}

Carlsen, J. C. (1981). Some factors which influence melodic expectancy. Psychomusicology, 1, 12-29.

Carlsen, J. C. (1990). Preface. Psychomusicology, 9, 119-121.

Cuddy, L. L., \& LunNey, C. A. (1995). Expectancies generated by melodic intervals: Perceptual judgments of melodic continuity. Perception \& Psychophysics, 57, 451-462.

JoneS, M. R. (1981). Music as a stimulus for psychological motion: Part 1. Some determinants of expectancies. Psychomusicology, 1, 34-51.

JoNES, M. R. (1982). Music as a stimulus for psychological motion: Part 2. An expectancy model. Psychomusicology, 2, 1-13.

Jones, M. R. (1990). Learning and the development of expectancies: An interactionist approach. Psychomusicology, 9, 193-228.

Krumhansl, C. L. (1991). Melodic structure: Theoretical and empirical descriptions. In J. Sundberg, L. Nord, \& R. Carlson (Eds.), Music, language, speech and brain (pp. 269-283). London: Macmillan.

KRUMHANSL, C. L. (1995). Music psychology and music theory: Problems and prospects. Music Theory Spectrum, 17, 53-80.

Krumhansl, C. L., \& Kessler, E. (1982). Tracing the dynamic changes in perceived tonal organization in a spatial representation of musical keys. Psychological Review, 89, 334-368.

MEYER. L. B. (1956). Emotion and meaning in music. Chicago: University of Chicago Press.

Narmour, E. (1989). The "genetic code" of melody: Cognitive structures generated by the implication-realization model. Contemporary Music Review, 4, 45-63.

NARMOUR, E. (1990). The analysis and cognition of basic melodic structures. Chicago: University of Chicago Press.

NARMOUR, E. (1992). The analysis and cognition of melodic complexity. Chicago: University of Chicago Press. 
Palmer, C. (1992). The role of interpretive preferences in music performance. In M. R. Jones \& S. Holleran (Eds.), Cognitive bases of musical communication (pp. 249-262). Washington, DC: American Psychological Association.

SCHELlenberg, E. G. (1996). Expectancy in melody: Tests of the implication-realization model. Cognition, 58, 75-125.

SCHMUCKLER, M. A. (1989). Expectation in music: Investigation of melodic and harmonic processes. Music Perception, 7, 109-150.

SCHMUCKLER, M. A. (1990). The performance of global expectations. Psychomusicology, 9, 122-147.

THOMPSON, W. F. (1996). Eugene Narmour: The analysis and cognition of basic melodic structures (1990) and The analysis and cognition of melodic complexity (1992): A review and empirical assessment. Journal of the American Musicological Society, 49, 127-145.

Thompson, W. F., \& Stainton, M. (1995/1996). Using humdrum to analyze melodic structure: An assessment of Narmour's implicationrealization model. Computing in Musicology, 10, 24-33.

UNYK, A. M., \& CARLSEN, J. C. (1987). The influence of expectancy on melodic perception. Psychomusicology, 7, 3-23.

\section{NOTES}

1. Narmour has described a number of procedures for identifying points of (unsuppressed) melodic implication. The first 2 notes of an unaccompanied melody are implicative unless they involve durational cumulation. More generally, melodic implication is strongest when there is movement away from metric stress and tonal stability, although harmony, style-specific factors, and other influences must also be considered. Conditions of melodic implication may be defined by just 2 successive notes (i.e., a melodic interval), and any interval that gives rise to melodic implication is referred to as an implicative interval. For a more complete review of the implication-realization model, see Thompson, 1996.

2. Participants were free to use the entire keyboard, so random responding could theoretically occur over a 5-octave range. Thus, our estimates of chance fulfillments using a 2-octave range were conservative. It would be inappropriate to estimate chance fulfillments using a smaller pitch range, however, because a small pitch range is one of the predictions of the principles. For example, the principle of proximity predicts that continuation notes will be 5 semitones or less from the 2nd note of the implicative interval.

3. An odds ratio of 1.0 indicates that the odds of a response's fulfilling the principle is equal to the odds of a response's not fulfilling the principle. For dummy-coded variables, the odds ratio is the odds that a response fulfills the principle divided by the odds that a response does not fulfill the principle. For example, an odds ratio of 5.8 (see Table 4, low-training, registral direction) means that the odds that a response fulfills the principle of registral direction is 5.8 times the odds that a response does not fulfill the principle. For graded principles, the odds ratio applies to each unit increase. For example, an odds ratio of 1.15 for proximity (see Table 4 , low-training) means that the odds of a response's occurring at coded value "6" is 1.15 times the odds of a response's occurring at coded value " 5 ," which is 1.15 times the odds of a response's occurring at coded value " 4 ," and so on.

4. Another way to separate the predictive power of tonality from that of Narmour's principles is to model continuation tones that are nondiatonic to the implied key. The approach was not possible for the present data because there were too few nondiatonic responses. However, in a reanalysis of Cuddy and Lunney's (1995) data, the five bottomup principles (as described in their final model) were entered as predictors of mean ratings, excluding all continuation tones that fulfilled the tonal region predictor (the strongest tonality predictor in the study). All predictors made a significant contribution to the model, and the multiple $R$ value, .77 , was close to that reported by Cuddy and Lunney for the full data set when tonal region was included as a predictor $(R=$ $.80)$. The result suggests that the five bottom-up principles account for about $60 \%$ of the variance in mean ratings that cannot be attributed to tonality.

\section{APPENDIX}

Frequency of continuation notes selected by musically trained and musically untrained listeners following eight implicative intervals. The first note of all implicative intervals was $\mathrm{C}_{4}$.

\begin{tabular}{|c|c|c|c|c|c|c|c|c|}
\hline \multirow{2}{*}{$\begin{array}{l}\text { Pitch } \\
\text { of Third } \\
\text { Note }\end{array}$} & \multicolumn{2}{|c|}{$\begin{array}{l}\text { Major } \\
\text { Second }\end{array}$} & \multicolumn{2}{|c|}{$\begin{array}{l}\text { Minor } \\
\text { Third }\end{array}$} & \multicolumn{2}{|c|}{$\begin{array}{l}\text { Major } \\
\text { Sixth }\end{array}$} & \multicolumn{2}{|c|}{$\begin{array}{c}\text { Minor } \\
\text { Seventh } \\
\end{array}$} \\
\hline & A & D & A & D & A & D & A & D \\
\hline
\end{tabular}

\begin{tabular}{|c|c|c|c|c|c|c|c|c|}
\hline \multicolumn{9}{|c|}{ Trained Listeners } \\
\hline $\mathrm{C}_{3}$ & 0 & 0 & 0 & 0 & 0 & 1 & 0 & 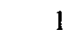 \\
\hline $\mathrm{C}_{3}{ }_{3}$ & 0 & 0 & 0 & 0 & 0 & 0 & 0 & c \\
\hline$D_{3}$ & 1 & 1 & 0 & 2 & 0 & 4 & 0 & \\
\hline $\mathrm{D}_{3}$ & 0 & 0 & 0 & 0 & 0 & 0 & 0 & \\
\hline$E_{3}$ & 0 & 0 & 0 & 1 & 0 & 5 & 0 & 13 \\
\hline$F_{3}$ & 0 & 2 & 0 & 4 & 0 & 12 & 0 & 11 \\
\hline $\mathrm{FH}_{3}$ & 0 & 0 & 0 & 0 & 0 & 1 & 0 & \\
\hline $\mathrm{G}_{3}$ & 1 & 9 & 1 & 12 & 0 & 9 & 0 & \\
\hline $\mathrm{G}_{3}$ & 0 & 4 & 0 & 0 & 0 & 2 & 0 & \\
\hline $\mathrm{A}_{3}$ & 0 & 16 & 0 & 2 & 0 & 4 & 0 & \\
\hline $\mathrm{AH}_{3}$ & 1 & 1 & 0 & 3 & 0 & 0 & 2 & \\
\hline $\mathrm{B}_{3}$ & 0 & 4 & 1 & 11 & 0 & 1 & 0 & \\
\hline $\mathrm{C}_{4}$ & 12 & 9 & 10 & 9 & 5 & 10 & 5 & \\
\hline $\mathrm{CH}_{4}$ & 1 & 0 & 0 & 1 & 0 & 0 & 0 & \\
\hline $\mathrm{D}_{4}$ & 1 & 1 & 7 & 2 & 3 & 0 & 2 & \\
\hline $\mathrm{D}_{4}$ & 0 & 0 & 0 & 1 & 0 & 1 & 0 & \\
\hline$E_{4}$ & 15 & 1 & 7 & 1 & 5 & 0 & 1 & \\
\hline$F_{4}$ & 7 & 0 & 9 & 0 & 12 & 0 & 5 & \\
\hline $\mathrm{F}_{4}$ & 0 & 0 & 0 & 0 & 0 & 0 & 2 & \\
\hline $\mathrm{G}_{4}$ & 8 & 2 & 10 & 0 & 19 & 0 & 14 & \\
\hline $\mathrm{G}_{4}$ & 0 & 0 & 1 & 0 & 0 & 0 & 0 & \\
\hline $\mathrm{A}_{4}$ & 3 & 0 & 4 & 1 & 2 & 0 & 10 & \\
\hline $\mathrm{A}_{4}$ & 0 & 0 & 0 & 0 & 1 & 0 & 1 & \\
\hline $\mathbf{B}_{4}$ & 0 & 0 & 0 & 0 & 2 & 0 & 3 & \\
\hline $\mathrm{C}_{5}$ & 0 & 0 & 0 & 0 & 1 & 0 & 4 & \\
\hline$C \#_{5}$ & 0 & 0 & 0 & 0 & 0 & 0 & 0 & \\
\hline$D_{5}$ & 0 & 0 & 0 & 0 & 0 & 0 & 1 & \\
\hline
\end{tabular}

\begin{tabular}{|c|c|c|c|c|c|c|c|}
\hline \multicolumn{8}{|c|}{ Untrained Listeners } \\
\hline $\mathrm{C}_{3}$ & 0 & 0 & 0 & 0 & 0 & 1 & 0 \\
\hline $\mathrm{CH}_{3}$ & 0 & 0 & 0 & 0 & 0 & 0 & 0 \\
\hline $\mathrm{D}_{3}$ & 1 & 0 & 0 & 1 & 0 & 2 & 0 \\
\hline $\mathrm{D}_{3}$ & 0 & 0 & 0 & 0 & 0 & 2 & 0 \\
\hline $\mathrm{E}_{3}$ & 0 & 1 & 0 & 2 & 0 & 5 & 0 \\
\hline$F_{3}$ & 1 & 3 & 0 & 3 & 0 & 9 & 0 \\
\hline $\mathrm{FH}_{3}$ & 0 & 1 & 1 & 0 & 0 & 0 & 0 \\
\hline $\mathrm{G}_{3}$ & 2 & 6 & 0 & 14 & 0 & 6 & 0 \\
\hline $\mathrm{G}_{3}$ & 0 & 3 & 0 & 4 & 0 & 1 & 0 \\
\hline $\mathrm{A}_{3}$ & 0 & 14 & 0 & 1 & 0 & 9 & 0 \\
\hline $\mathrm{A} \#_{3}$ & 0 & 0 & 0 & 1 & 0 & 0 & 0 \\
\hline $\mathrm{B}_{3}$ & 1 & 4 & 0 & 10 & 2 & 2 & 0 \\
\hline $\mathrm{C}_{4}$ & 15 & 10 & 9 & 7 & 4 & 11 & 6 \\
\hline $\mathrm{CH}_{4}$ & 0 & 1 & 2 & 0 & 0 & 0 & 0 \\
\hline $\mathrm{D}_{4}$ & 1 & 3 & 3 & 1 & 2 & 1 & 4 \\
\hline $\mathrm{D} \#_{4}$ & 2 & 1 & 0 & 1 & 1 & 1 & 0 \\
\hline$E_{4}$ & 15 & 2 & 9 & 2 & 5 & 0 & 2 \\
\hline $\mathrm{F}_{4}$ & 3 & 0 & 9 & 2 & 12 & 0 & 5 \\
\hline $\mathrm{F}_{4}$ & 0 & 0 & 2 & 0 & 0 & 0 & 3 \\
\hline $\mathrm{G}_{4}$ & 6 & 0 & 8 & 1 & 14 & 0 & 11 \\
\hline $\mathrm{G}_{4}$ & 0 & 0 & 0 & 0 & 2 & 0 & 0 \\
\hline $\mathrm{A}_{4}$ & 0 & 0 & 6 & 0 & 4 & 0 & 12 \\
\hline $\mathrm{A}_{4}$ & 0 & 1 & 1 & 0 & 0 & 0 & 2 \\
\hline $\mathrm{B}_{4}$ & 2 & 0 & 0 & 0 & 2 & 0 & 3 \\
\hline $\mathrm{C}_{5}$ & 1 & 0 & 0 & 0 & 1 & 0 & 2 \\
\hline $\mathrm{CH}_{5}$ & 0 , & 0 & 0 & 0 & 0 & 0 & 0 \\
\hline$D_{5}$ & 0 & 0 & 0 & 0 & 1 & 0 & 0 \\
\hline
\end{tabular}

Note--The implicative intervals are in the ascending (A) and descending (D) directions. 